\title{
The Dilemma of the Dilated Main Pancreatic Duct in the Distal Pancreatic Remnant After Proximal Pancreatectomy for IPMN
}

Rachel E. Simpson MD ${ }^{\mathrm{a}}$, Eugene P. Ceppa MD ${ }^{\mathrm{a}, \mathrm{b}}$, Howard H. Wu MD ${ }^{\mathrm{c}}$, Fatih Akisik MD ${ }^{\mathrm{d}}$, Michael G. House MD ${ }^{\mathrm{a}}$, Nicholas J. Zyromski MD ${ }^{\mathrm{a}}$, Attila Nakeeb MD ${ }^{\mathrm{a}}$, Mohammad A. Al-Haddad MD ${ }^{\mathrm{b}, \mathrm{e}}$, John M. DeWitt MD ${ }^{\mathrm{e}}$, Stuart Sherman MD ${ }^{\mathrm{e}}, \mathrm{C}$. Max Schmidt MD/MBA/PhD ${ }^{\mathrm{a}, \mathrm{b}, \mathrm{f}-\mathrm{h}}$

${ }^{\text {a }}$ Department of Surgery, Indiana University School of Medicine, Indianapolis, IN

${ }^{\mathrm{b}}$ Indiana University Health Pancreatic Cyst and Cancer Early Detection Center, Indianapolis, IN

${ }^{\mathrm{c}}$ Department of Pathology and Laboratory Medicine, Indiana University School of Medicine, Indianapolis, IN

${ }^{\mathrm{d}}$ Department of Radiology, Indiana University School of Medicine, Indianapolis, IN

e Department of Medicine, Division of Gastroenterology, Indiana University School of Medicine, Indianapolis, IN

${ }_{\mathrm{f}}$ Department of Biochemistry/Molecular Biology, Indiana University School of Medicine, Indianapolis, IN

${ }^{\mathrm{g}}$ Walther Oncology Center, Indianapolis, IN

${ }^{\mathrm{h}}$ Indiana University Simon Cancer Center, Indianapolis, IN

\section{Correspondence Address:}

C. Max Schmidt, MD, PhD, MBA

Department of Surgery

Indiana University School of Medicine

545 Barnhill Drive, Emerson Hall 129

Indianapolis, IN 46202

Phone: (317) 948-8358Ｅ～Email: maxschmi@iupui.edu

Presentation: Selected for Plenary Presentation at the Digestive Disease Week annual meeting Washington, DC 6/3/2018

Financial Support: No external financial support or grant funding was used in this research study

Conflict of Interest (All Authors): No true conflict of interest relevant to this work. Consultants for Boston Scientific (Dr. Al-Haddad and Dr. Sherman)

\section{Author Contributions:}

Drs. Schmidt and Simpson: conception/design of the work; data acquisition, analysis, and interpretation; manuscript drafting/revision/final approval; agreement to accountability

Drs. Ceppa, Wu, Akisik, House, Zyromski, Nakeeb, Al-Haddad, DeWitt, Sherman: data acquisition/interpretation; manuscript revision/final approval; agreement to accountability

This is the author's manuscript of the article published in final edited form as:

Simpson, R. E., Ceppa, E. P., Wu, H. H., Akisik, F., House, M. G., Zyromski, N. J., ... Schmidt, C. M. (2019). The Dilemma of the Dilated Main Pancreatic Duct in the Distal Pancreatic Remnant After Proximal Pancreatectomy for IPMN. Journal of Gastrointestinal Surgery, 23(8), 1593-1603. https://doi.org/10.1007/s11605-018-4026-0 


\section{ABSTRACT}

OBJECTIVE(S): A dilated main pancreatic duct in the distal remnant after proximalpancreatectomy for IPMN poses a diagnostic dilemma. We sought to determine parameters predictive of remnant main-duct IPMN and malignancy during surveillance.

METHODS: 317 patients underwent proximal-pancreatectomy for IPMN (Indiana University 1991-2016). Main-duct dilation included those $\geq 5 \mathrm{~mm}$ or "dilated" on radiographic reports. Statistics compared groups using Student's T/Mann-Whitney U-tests for continuous variables, or Chi-Square/Fisher's Exact test for categorical variables with $\mathrm{P}<0.05$ considered significant. RESULTS: High-Grade/Invasive-IPMN or adenocarcinoma at proximal-pancreatectomy predicted malignant outcomes $(100.0 \%$ malignant outcomes; $\mathrm{P}<0.001)$ in remnant surveillance. Low/Moderate-Grade lesions revealed benign outcomes at last surveillance regardless of duct diameter. Twenty of 21 patients undergoing distal remnant re-operation had a dilated main-duct. Seven had main-duct IPMN on remnant pathology; these patients had greater mean maximum main-duct diameter prior to re-operation ( $9.5 \mathrm{vs} 6.2 \mathrm{~mm}, \mathrm{P}=0.072)$ but this did not reach statistical significance. Several features showed high sensitivity/specificity for remnant mainduct IPMN.

CONCLUSIONS: Remnant main-duct dilation after proximal-pancreatectomy for IPMN remains a diagnostic dilemma. Several parameters show promise in accurately diagnosing mainduct IPMN in the remnant.

KEYWORDS: Pancreatic Duct, Pancreatic Neoplasms, Mucinous Neoplasms, Pancreatic Cyst, Pancreaticoduodenectomy 


\section{$\underline{\text { INTRODUCTION }}$}

Since the first description in 1982,[1] intraductal papillary mucinous neoplasms (IPMN) have become increasingly recognized as one of the most common cystic lesions of the pancreas.[2] Because of the variable risk of malignant transformation, the International Consensus guidelines were developed to aid clinicians in deciding which patients had higher-risk lesions and should undergo surgical resection. $[3,4]$ The risk of progression of residual disease or the development of new IPMN or even ductal adenocarcinoma in the remnant pancreas has been recognized. The incidence of recurrent IPMN in the remnant pancreas after resection is reported between 5.8\% and $14.4 \%$ in the literature.[5-13] These figures support ongoing surveillance of the remaining pancreas, even if the index IPMN lesion has been removed in its entirety.

Because of the approximately $60 \%$ risk of progression to malignant disease,[4] the presence of Main-Duct Involved IPMN (MD-IPMN: Main-Duct or Mixed-Type IPMN) in the remnant pancreas warrants further resection. The diagnosis of MD-IPMN is often made by unexplained dilation of the main pancreatic duct (MPD), abrupt changes in MPD caliber with distal gland atrophy, or through endoscopic ultrasound (EUS) examining for thickened walls or intraductal mucin suggestive of MPD involvement.[4] However, the distal pancreatic remnant (DPR) after proximal-pancreatectomy (PP) poses a unique and important diagnostic dilemma. In the setting of a pancreato-enteric anastomosis, a dilated MPD cannot automatically be interpreted as MD-IPMN. In these cases, the presence of a dilated MPD holds a much broader differential diagnosis.

A dilated MPD after PP may reflect MD-IPMN, anastomotic stricture or ductal obstruction with upstream MPD dilation, pancreatitis with gland atrophy, the natural history of 
the DPR, or a combination thereof.[14-18] Accurate diagnosis in these patients is important, because the recommended treatments are vastly different. While MD-IPMN are generally resected, alternate diagnoses depending upon the presence and severity of symptoms may be treated expectantly, non-operatively or with advanced endoscopic techniques.[16, 19-25] Reoperation may include anastomotic revision, in which only a small segment of the pancreas is removed. In cases with diffuse remnant disease requiring completion pancreatectomy, an apancreatic state is created with resulting endocrine and exocrine insufficiency. While surgical resection would provide the diagnosis and potentially treat the disease, this must be balanced with the known $>30 \%$ morbidity associated with pancreatic surgery regardless of approach.[26] Though endoscopic techniques may provide diagnostic and therapeutic value, because of altered post-surgical anatomy, potential structuring, or angulation of the MPD, variable success has been reported for both Endoscopic Retrograde Cholangio-Pancreatography (ERCP) and the challenging Endoscopic Rendezvous procedure.[19, 22, 27-30] Several prior studies have attempted to identify the cross-sectional imaging features of MD-IPMN, pancreatitis, the "normal" postoperative pancreas, or anastomotic strictures, but to our knowledge none have distinguished between MD-IPMN and other pathologies in the DPR specifically.[31-33]

The aim of our study was to evaluate the postoperative diagnostic techniques and outcomes for patients who underwent PP for IPMN. We sought to determine which features may predict MD-IPMN on DPR re-operative surgical pathology. Our other goal was to better understand the natural history of the DPR with/without a dilated MPD after PP for IPMN, and better manage those with MPD dilation in an evidence-based manner. 


\section{METHODS}

\section{Study Population Criteria}

We retrospectively reviewed a prospectively maintained database of 537 patients who underwent surgical resection for IPMN between 1991 and 2016 at Indiana University. Patients who had undergone either pancreatoduodenectomy (PD) or central pancreatectomy (CP) resulting in a left (distal) pancreatic remnant (DPR) with a pancreato-enteric (gastric or jejunal) anastomosis were eligible. We refer to either PD or CP as "proximal-pancreatectomy" (PP). Patients without available cross-sectional imaging/endoscopy reports postoperatively were excluded. Cross-sectional imaging $(n=1,172)$, endoscopic $(n=111)$, DNA profiling $(n=32)$, clinical and surgical pathology reports were reviewed. Data were gathered and recorded in accordance with the Indiana University Institutional Review Board guidelines.

For those who underwent re-operation of the DPR, the primary outcome was MD-IPMN on surgical pathology. For those undergoing only surveillance after PP, the primary outcome was defined as overall benign or malignant. A malignant outcome was determined by recurrent, invasive mass lesion, peritoneal carcinomatosis, or metastatic disease on cross-sectional imaging, or cytology/biopsy revealing malignancy.

We compared groups using the Student's T/Mann-Whitney U-test for continuous variables depending on normality of data, and the Chi-Square/Fisher's Exact test for categorical variables. Proportions, mean and standard error of the mean (SEM), median and range were calculated when appropriate. An $\alpha$-level of 0.05 was considered statistically significant. IBMSPSS software, version 24 was used.

\section{Variable Definitions}


1) MPD Dilation: measurement $\geq 5 \mathrm{~mm}$ on cross-sectional imaging or endoscopy, or MPD described as "dilated;" those only "mildly dilated/mildly prominent" were not included

2) Surgeon's Suspicion for MD-IPMN: surgeon noted concern for MD-IPMN as a reason for reoperation in preoperative documentation

3) Endoscopist's Suspicion for MD-IPMN: gastroenterologist noted concern for MD-IPMN in the endoscopy report

4) Exocrine Insufficiency: documentation of steatorrhea/diarrhea, or prescription of pancreatic digestive enzymes

5) Weight Loss: patient-reported unintended weight loss (any magnitude) post-PP

6) DNA Parameters: High Quantity DNA (any value other than "Low" Quantity DNA); High Quality DNA (any value other than "Poor" Quality DNA); KRAS/GNAS mutation; Allelic loss of heterozygosity ( $\mathrm{LOH}$ ) of tumor suppressor genes on MPD fluid aspirates

7) Positive Margin at PP: includes side-branch/main-duct margins positive for IPMN or PanIN, all grades. PanIN falls on a similar spectrum of neoplastic lesions as IPMN. Often, the distinction between the two pathologies is dependent on size of the lesion: this would be difficult to assess at a surgical margin. In order to be most inclusive of all possible residual IPMN at the PP margin, we included PanIN in this definition.

\section{Our Institutional Surveillance Protocol}

After initial evaluation and establishment of a diagnosis of likely IPMN, follow-up is individualized based on a number of factors. These include worsening of symptoms, trends in laboratory values to suggest pancreatic insufficiency/inflammation (Hemoglobin A1c, c-peptide, amylase/lipase), CA19-9 trends, evolution of lesions on radiographic imaging or endoscopy, or concerning features on cyst fluid analysis (cytology and molecular profiling). After an initial 3-4 
week postoperative visit, similar criteria are considered to guide surveillance after proximal pancreatectomy or DPR re-operation. In general, patients are followed every 6-12 months (or in rare instances at a 3-month interval) with history and physical exam, radiographic imaging, and a panel of laboratory tests (Hemoglobin A1c, c-peptide, CEA, CA19-9, Alkaline Phosphatase, Bilirubin, Amylase, Lipase). Patients with a persistently dilated pancreatic duct $\geq 4 \mathrm{~mm}$ that is not steadily decreasing in size are followed every 6 months. Depending on stratification to a high- or low-risk protocol, patients are generally recommended for endoscopic evaluation every 3-5 years.

\section{RESULTS}

A total of 537 patients underwent surgical resection for IPMN between September 1991 and September 2016. Of these, 317 had undergone PP (PD: $n=306,56.9 \%$; CP: $n=11,2 \%$ ). Seventy-two patients (1 from DPR re-operative group, 71 from DPR surveillance-only group) were excluded due to lack of available diagnostic studies during surveillance or prior to reoperation of the DPR. Most ( $\mathrm{n}=224,91.4 \%)$ of the remaining 245 patients underwent DPR surveillance without re-operation. The other 21 patients $(8.6 \%)$ underwent subsequent DPR resection (anastomotic revision or completion pancreatectomy). Based on pre-operative documentation, the indications for DPR resection were as follows: concern for PJ stricture \pm symptoms $(n=5)$, concern for MD-IPMN \pm symptoms $(n=11)$, concern for MD-IPMN OR PJ stricture (i.e. both mentioned) $(n=3)$, symptoms without presumed etiology provided $(n=2)$.

\section{DPR Surveillance Cohort}

Of the 224 patients in the DPR surveillance cohort, at the time of PP, 90 (40.2\%) patients had High-Grade Dysplasia (HGD) or Invasive disease; 120 (53.6\%) patients had MD-IPMN, and 
55 (24.6\%) patients had any positive margins (PanIN or IPMN of any grade) on pathology. Only 3 of these were HGD-IPMN ( $\mathrm{n}=2$ ) or Invasive-IPMN ( $\mathrm{n}=1)$, which were up-graded on permanent pathology from indeterminate/unclear or only "suspicious" frozen section diagnoses. Neither the presence of any positive margin, nor HGD/Invasive-IPMN at the margin specifically, were associated with a malignant outcome $(\mathrm{P}>0.05)$. Seventy-one patients $(31.7 \%)$ had a dilated MPD during surveillance, with a median time to first dilated duct at 365 days (5-3651 days) and maximum duct diameter at 432 days (7-3651 days). The median maximum diameter for those with a dilated MPD was $6 \mathrm{~mm}(5-13 \mathrm{~mm})$.

A total of $24(10.7 \%)$ patients were determined to have a malignant outcome during DPR surveillance, with a median time to diagnosis of 203 days (28-2031 days). Of the 200 (89.3\%) patients with a benign outcome, the median benign surveillance period was 980 days (4-7246 days). Of these patients, 153 (76.5\%) were followed for $\geq 1$ year, and $122(61.0 \%)$ for $\geq 2$ years. When examining clinical, radiographic, and endoscopic factors, only a history of HGD/Invasive pathology on PP and CA19-9 levels during DPR surveillance were significantly associated with a malignant outcome. (Table 1) Of note, due to occasional missing retrospective data, or certain variables only pertinent to patients with a dilated MPD, the denominators throughout Table $\mathbf{1}$ are inconsistent. Please see the table footnote for further clarification of the data presented.

Twenty-four of the $24(100 \%)$ patients with a malignant outcome had HGD (1 of 24; $4.2 \%$ ) or Invasive ( 23 of $24 ; 95.8 \%$ ) pathology at the time of PP. None of 126 patients $(0.0 \%)$ with Low/Moderate grade IPMN at the time of PP were found to have a malignant outcome at most recent surveillance. This association between HGD/Invasive lesions at PP and a malignant outcome during DPR surveillance was highly significant $(\mathrm{P}<0.001)$. In contrast, 66 of the 200 patients (33.0\%) with a benign outcome had HGD (34 of 200; 17.0\%) or Invasive (32 of 200; 
$16.0 \%)$ disease at the time of PP. Figure 1 depicts the proportion of benign versus malignant outcomes by PP-pathologic grade. For patients with prior Low/Moderate IPMN, the median benign surveillance period was 1,010 days (6-6,460 days). The patient with prior HGD-IPMN with a malignant outcome was diagnosed much earlier (601 days) compared to those with a benign surveillance period of 1,379 days (4-4,549 days). Overall, follow-up was shorter for patients with prior Invasive lesions, with median times to malignant (191 days; 28-2,031 days) and benign (289 days; 7-3,246 days) outcome diagnoses. These follow-up data are summarized in Figure 2.

During DPR surveillance, patients with malignant outcomes had significantly greater maximum CA19-9 levels (669 U/mL; 3-67,107 U/mL) compared to patients with benign surveillance $(23 \mathrm{U} / \mathrm{mL} ; 1-81,954 \mathrm{U} / \mathrm{mL})(\mathrm{P}<0.001)$. However, there was overlap in their ranges. Similarly, the patient's most recent CA19-9 level was greater for patients with a malignant outcome (556 U/mL; 3-67,107 U/mL) compared to those with overall benign follow-up (18 $\mathrm{U} / \mathrm{mL} ; 1-81,954 \mathrm{U} / \mathrm{mL})(\mathrm{P}<0.001)$. No other factors were predictive of a malignant outcome. Namely, no variables involving MPD dilation or timing of MPD diameter fluctuations predicted a malignant outcome during surveillance of the DPR. The variables examined are compared between benign and malignant outcome groups in Table 1. Only a small number of patients in the DPR-Surveillance group underwent endoscopic MPD fluid aspiration analysis, making meaningful interpretation in the present study difficult. Only one patient had concerning cytology which proved to be recurrent carcinoma. These data are summarized in Supplemental

\section{Table 1a.}

DPR Re-Operative Cohort 
Twenty-one patients were included in the DPR re-operative cohort. On PP pathology, 7 (33.3\%) patients had HGD/Invasive disease; 12 (57.1\%) patients had MD-IPMN, and 4 (19.0\%) had positive margins (all Low/Moderate-IPMN or PanIN 1-2). Nearly all (20 of 21; 95.2\%) patients had a dilated MPD duct at some point between PP and DPR re-operation. The median time to the first dilated MPD was 374 days (8-2651 days) whereas the median time to the maximum MPD diameter was 624 days (112-2993 days). Of patients with a dilated MPD in the DPR, the median maximum diameter was $7 \mathrm{~mm}(5-16 \mathrm{~mm})$.

Seven of the 21 patients (33.3\%) that underwent DPR surgery had MD-IPMN on DPR pathology (6 Low/Moderate-IPMN, 1 Invasive-IPMN). These patients underwent DPR surgery a median time of 1772 days (148-3815 days) post-PP, which was later than those who underwent DPR surgery and had other diagnoses, at 1296 days (450-4928 days). Other diagnoses on DPR pathology included Low/Moderate-Grade Side-Branch IPMN with Pancreatitis ( $\mathrm{n}=5)$, Pancreatitis ( $\mathrm{n}=7)$, Duct Ectasia with Gland Atrophy $(\mathrm{n}=1)$ and Small Intestine Adenocarcinoma with Pancreatitis $(\mathrm{n}=1)$.

All patients with MD-IPMN on DPR pathology had a dilated MPD at some point post-PP (7 of 7, 100.0\%). Of all clinical, radiographic, and endoscopic features considered, the maximum MPD diameter between PP and DPR surgery was the strongest predictor of MD-IPMN in the DPR. Patients with MD-IPMN had a mean maximum MPD diameter of $9.5 \mathrm{~mm}$ (SEM 1.5mm) compared to only $6.2 \mathrm{~mm}$ (SEM $0.5 \mathrm{~mm}$ ) for those with other diagnoses $(\mathrm{P}=0.072)$. Likely due to small sample size, this missed reaching statistical significance. The median time to maximum duct diameter was 618 days (112-2993 days) for those with MD-IPMN compared to 801 days (187-2740) for those with other diagnoses $(\mathrm{P}=1)$. 
Receiver operating characteristic (ROC) curve analysis was performed, and a maximum MPD diameter cutoff of $6.5 \mathrm{~mm}$ provided $85.7 \%$ sensitivity and $69.2 \%$ specificity for MD-IPMN in the DPR, with an area under the curve of 0.780 . (Figure 3) One in $10(10 \%)$ patients with maximum MPD diameter before DPR $<6.5 \mathrm{~mm}$ had MD-IPMN on DPR pathology, whereas 6 of $10(60 \%)$ patients with a maximum MPD diameter $\geq 6.5 \mathrm{~mm}$ had MD-IPMN on DPR pathology. One patient had a MPD described as "dilated" without a specific measurement, thus were excluded from this analysis.

Several features were highly specific for MD-IPMN in the DPR. A high suspicion for MD-IPMN noted by the endoscopist was $83.3 \%$ specific for MD-IPMN with PPV of $60.0 \%$, but lacked sensitivity (42.9\%). On MPD fluid aspirate, the presence of HGD or carcinoma on cytology, High Quality DNA, KRAS/GNAS mutation, or allelic LOH provided $>80 \%$ specificity for MD-IPMN, but often lower sensitivity $(0.0 \%-66.7 \%)$, as many duct fluid aspirates do not display these features. These were examined in only a small number of patients $(n=6-13)$. (Supplemental Table 1b) The presence of a normal ductogram (i.e. normal contrast flow through the pancreato-enteric anastomosis) was $87.5 \%$ specific for MD-IPMN, but poorly sensitive at only $33.3 \%$. Thus, most individuals with other diagnoses will display an abnormal ductogram. The most sensitive features associated with MD-IPMN were the presence of exocrine insufficiency and High Quantity DNA on MPD fluid aspirate, occurring in 100\% of cases. The surgeon expressed concern for MD-IPMN at the time of DPR re-operation in $71.4 \%$ of cases revealing MD-IPMN on DPR pathology. None of these highly sensitive features were specific for MD-IPMN. Though sensitive or specific, these variables did not reveal statistically significant associations with MD-IPMN on DPR surgical pathology $(\mathrm{P}>0.05)$. These features are summarized in Table 2. Similar to our analysis of the DPR surveillance cohort, the denominators 
throughout Table 2 and Supplemental Table 1 may change depending on availability of retrospective data, certain variables only pertinent to patients with a dilated MPD, or certain procedures (endoscopy with pancreatic fluid analysis) only performed on a subset of patients. This is further clarified in the table footnote. Based on these data and our institution's practice, we proposed an algorithm for management of the DPR in the setting of a dilated MPD. (Figure

4)

\section{DISCUSSION}

The fate of the pancreatic remnant after resection for IPMN has been examined a number of ways. Several prior studies have determined that the rate of metachronous IPMN in any remnant pancreas is not negligible, between 5.8\% and 14.4\%.[5-13] The concern with IPMN is a potential for progression to invasive cancer. Miller et al. reported that $2 \%$ of individuals who underwent resection for non-invasive IPMN went on to develop invasive cancer in the remnant pancreas.[34] In a report from Moriya and Traverso, a similarly low rate (2 of 203 patients; 1\%) of invasive cancer in the remnant pancreas was noted; both of these patients had a prior history of HGD/Invasive disease.[9] In a study of the remnant pancreas after initial resection for MDIPMN specifically, the rate of recurrence in the form of metastases (11\%) or HGD/Invasive lesions in the pancreatic remnant (13\%) was much greater than other reports; 6$]$ this difference may underline the more aggressive nature of MD-IPMN. Because of the higher rate of progression to $\mathrm{HGD} /$ Invasive disease, the detection of MD-IPMN in the remnant is of upmost importance. These prior studies examined the pancreatic remnant in general but not the unique dilemma presented by the DPR after PP. While a dilated MPD generally suggests MD-IPMN, in the setting of a DPR with a pancreato-enteric anastomosis, the range of possible diagnoses is broad. To our knowledge, the present study is the first comprehensive evaluation of the DPR 
after PP, examining the radiographic, clinical, and endoscopic techniques utilized to predict the occurrence of MD-IPMN and malignant outcomes in this specific population.

We examined the DPR natural history for 245 patients that initially underwent PP for IPMN and found a dilated MPD to be common (37.1\% of the entire cohort). Many of the 224 patients undergoing only DPR surveillance $(\mathrm{n}=71 ; 31.7 \%)$ had a dilated MPD at some point, with a median time to first dilation of 365 days; furthermore, the median maximum diameter of the MPD during surveillance was $6 \mathrm{~mm}$ at a median time of 432 days after PP. Because these individuals did not undergo re-operative surgery, we were unable to determine if this MPD dilation represented MD-IPMN or an alternate diagnosis. However, the presence of a dilated MPD during surveillance of the DPR, the maximum diameter of the MPD during surveillance, and the timing of these fluctuations did not predict a malignant outcome. In contrast to the International Consensus Guidelines recommendations for surgical resection of patients with dilated MPD in a pre-operative pancreas,[4] in the setting of a dilated MPD in the DPR after PP, our findings do not support automatic surgical resection to prevent a malignant outcome.

The strongest predictor of a malignant outcome was the presence of HGD/Invasive disease at PP, with median time to malignant outcome of 203 days (75\% of individuals diagnosed within 632 days). Thus, most patients with a history of HGD/Invasive disease will present with a recurrence or progression of their malignancy within 2 years of PP. The majority ( 66 of 90; 73.3\%) of patients with HGD/Invasive disease ultimately had a benign outcome at most recent surveillance, at a median time of 834 days, including those with a dilated MPD $(n=21 ; 31.8 \%)$. These findings support rigorous surveillance for evidence of malignant progression, especially in the years immediately following PP, for patients with a history of HGD/Invasive disease regardless of MPD diameter. In our cohort, no individuals with 
Low/Moderate-Grade IPMN at the time of PP went on to develop evidence of malignancy during DPR surveillance, with a median follow-up period of 1010 days. These data may support ongoing surveillance and diagnostic evaluation of patients with a history of Low/ModerateGrade disease, even in the presence of a dilated MPD $(n=45 ; 35.7 \%)$ over immediate surgical resection.

The other factor predicting a malignant outcome in the present study was a greater CA199 level, both maximum and most recent values after PP. While this association between greater CA 19-9 level and increasing grade of IPMN has been demonstrated in the literature, [35, 36] others have not validated this relationship.[37] In a prior study by Park et al., an elevated CA 199 level preceding surgery was found to be associated with disease recurrence after resection of IPMN; 12 of 13 recurrent cases had invasive disease at the time of index operation, and 10 of the 13 patients had recurrence outside of the remnant pancreas suggesting advanced, metastatic disease.[13] This prior report approximates our findings and the relationship between prior HGD/Invasive pathology, elevated CA 19-9 level, and malignant outcomes. However, in contrast to the pre-operative CA 19-9 levels described in these prior studies, the CA 19-9 levels described in the present study are reflective of the post-PP surveillance of the DPR.

In the DPR re-operative cohort, only 2 individuals had aggressive lesions (1 small bowel adenocarcinoma, 1 invasive-IPMN). While it may be argued that only 2 patients benefitted from DPR resection, the benefit of symptomatic relief and clarification of pathology (MD-IPMN vs alternate diagnoses) to better guide management cannot be ignored. Once we are able to reliably establish a diagnosis of MD-IPMN in the DPR, efforts focused on isolating only the highest-risk lesions (HGD/Invasive-IPMN) should be undertaken. Because one of the most reliable features of the International Consensus Guidelines, MPD diameter, is confounded in this post-PP 
population, the future of diagnosing HGD/Invasive-IPMN in this population will likely rely on more individualized assessment through cyst fluid/serum molecular profiling or biomarker analyses. The present study has limited molecular data available on a small number of patients and should be the focus of future studies.

While predicting which individuals will have a malignant outcome after resection of IPMN is difficult, determining which patients have a MD-IPMN in the setting of a DPR after PP is the first challenge in order to resect and potentially prevent progression to malignant disease. Conventional diagnostics including cross-sectional imaging and endoscopy are complicated by the altered foregut anatomy and pancreato-enteric anastomosis of a post-PP pancreas. For the pre-operative pancreas, the MPD diameter is of upmost importance in guiding resection of likely MD-IPMN in the International Consensus Guidelines. In the present study, all MD-IPMN diagnosed in the DPR had a maximum MPD diameter of at least $5 \mathrm{~mm}$; 6 of the $7(85.7 \%)$ patients with DPR MD-IPMN had a maximum MPD diameter of $\geq 7 \mathrm{~mm}$. This range corresponds with the minimum MPD diameter of $5 \mathrm{~mm}$ (considered a Worrisome Feature) to diagnose/evaluate for MD-IPMN by the 2012 International Consensus Guidelines.[4] In general, patients with MD-IPMN in the DPR had a greater maximum MPD diameter, with shorter time to maximum MPD diameter, compared to those with other diagnoses, but these findings did not reach statistical significance. Crippa et al. also reported a greater median MPD diameter for those with MD-IPMN compared to other diagnoses, though this prior study was of the preoperative pancreas rather than the DPR.[38] We determined that with a maximum MPD cutoff of $6.5 \mathrm{~mm}$, the sensitivity (85.7\%) and specificity (69.2\%) for MD-IPMN in the DPR were optimized. Based on these findings, patients with a maximum MPD $<6.5 \mathrm{~mm}$ in the DPR are unlikely to have MD-IPMN (only 1 of 10 patients), while 6 of $10(60 \%)$ of patients with a 
maximum dilated MPD $\geq 6.5 \mathrm{~mm}$ harbored MD-IPMN. These individuals particularly require further evaluation.

Advanced endoscopic techniques including endoscopic ultrasound (EUS) with or without fine needle aspiration (FNA) of cyst/duct fluid, or ERCP are performed to fully examine pancreatic lesions, gather biopsies, or treat obstructive pathology. While this can be a challenge in the post-PP patient, our data suggest that the information gathered from these diagnostic techniques are valuable for determining DPR pathology. In the present study, endoscopic evaluation by the gastroenterologist led to greater specificity, accuracy, and positive-predictive value for predicting MD-IPMN compared to the surgeon's suspicion. In our series, the gastroenterologist was more skilled at "ruling-in" MD-IPMN, which may help to reduce unnecessary surgical resection for non-neoplastic disease that may be managed non-operatively.

Features of MPD fluid aspirates gathered through EUS-FNA proved to be either highly sensitive or specific for MD-IPMN. The most specific DNA factors with the greatest positivepredictive value for MD-IPMN in the DPR included High Quality DNA, GNAS mutation, or allelic LOH. This is in accordance with prior reports, whereas High Quality DNA and LOH were associated with mucinous cysts [39, 40] and GNAS mutation predicted IPMN specifically.[41, 42] The most sensitive MPD aspirate features for MD-IPMN in the DPR were the presence of mucin $(80.0 \%)$ or High Quantity DNA $(100.0 \%)$. Because IPMN represent a neoplastic process characterized by mucin production, it follows that most patients with MD-IPMN would reveal mucin in the MPD upon aspiration. In a prior study by Morris-Stiff et al. mucin on cyst fluid aspirate was similarly found to be highly sensitive (80\%) but poorly specific ( $40 \%)$ for mucinous lesions.[43] The presence of High Quantity DNA on MPD fluid aspirate was highly sensitive $(100.0 \%)$ for MD-IPMN, but poorly specific (40.0\%). This is mechanistically reasonable. With a 
neoplastic process there may be greater cell turnover and DNA shedding into the cyst/ductal fluid. However, benign inflammatory processes, may also release cellular DNA into the cyst or ductal fluid.[44]

To fully visualize the pancreatic and biliary ductal system, ERCP may be employed. But in cases where ERCP is unsuccessful, the gastroenterologist may perform EUS-guided pancreatic ductography to gain access to and visualize the MPD.[45] With contrast injection into the MPD, in the present study, a ductogram revealing normal flow into the bowel (i.e. no anastomotic stricture or obstruction) was highly specific for MD-IPMN over an alternate diagnosis.

In general, clinical symptoms were not helpful in diagnosing MD-IPMN in the DPR. $100.0 \%$ of patients with MD-IPMN were noted to have exocrine insufficiency or be treated with pancreatic enzyme supplementation; however, because of the liberal use of pancreatic enzymes in the postoperative period for PP patients at our institution, this result is not surprising. Similarly, while abdominal pain was highly sensitive for MD-IPMN in the DPR (85.7\%), this was poorly specific, as many patients with alternate diagnoses (i.e. stricture or pancreatitis) also reported abdominal pain during DPR surveillance. The most specific (71.4\%) clinical indicator of MD-IPMN in the DPR was patient-reported unexplained weight loss, occurring twice as frequently in those with MD-IPMN (57.1\%) compared to those with other diagnoses in the DPR (28.6\%). While MD-IPMN, mucin, pancreatitis, or stricture of the pancreato-enteric anastomosis may all contribute to ductal obstruction, exocrine insufficiency, and ultimately weight loss,[46] it is unclear why this feature was reportedly more prominent in those with MD-IPMN in the present study. The surgeon was concerned about MD-IPMN in most cases, leading to high sensitivity but poor specificity for MD-IPMN in the DPR. This highlights the need for deliberate diagnostic evaluation often via endoscopy — and attempts at non-operative mitigation of any 
obstructive symptoms — as automatically operating based on the surgeon's suspicion for MDIPMN alone would lead to a large number of unnecessary surgeries for non-neoplastic disease (9 of 14 non MD-IPMN cases; 64.3\%).

Our study is limited by the nature of a retrospective data review. As some diagnostic studies did not have an actual MPD measurement, but were rather described as "dilated," "mildly dilated," or "mildly prominent," this variable was operationalized to avoid excluding data. The crux of this study is the diagnostic challenge of determining the presence of MD-IPMN in the DPR. As such, without surgical pathology, it was impossible to definitively determine the etiology of a dilated MPD in our surveillance cohort. Instead, we determined if these individuals had a benign or malignant outcome at follow-up. While some individuals in the benign group may still develop a metachronous malignancy in the future, we feel that the overall surveillance period for those determined to have a benign outcome was sufficient to allow time for this to occur. Many of our variables of interest did not reach statistical significance, likely due to an overall underpowered study with only 21 individuals undergoing re-operative DPR surgery, and only 24 malignant outcomes in the DPR surveillance cohort. Similarly, for a number of our analyses, very few patient samples were available for inclusion (i.e. MPD fluid aspirates). As such, this data should be interpreted cautiously. Future larger studies are necessary to validate our findings, determine statistically significant relationships, and add to the paucity of knowledge on this subject.

\section{CONCLUSION}

Dilation of the MPD in the DPR after PP is a common finding. The diagnostic dilemma stands in determining if this MPD dilation represents MD-IPMN, which requires surgical 
resection, versus an alternate diagnosis that may be managed non-operatively. While MPD dilation did not predict a malignant outcome, there is some evidence to suggest that the maximum diameter reached in the DPR may be slightly greater for MD-IPMN over other diagnoses. When the maximum MPD diameter is $<6.5 \mathrm{~mm}$, the rate of MD-IPMN in the DPR was only $10 \%$ compared to $60.0 \%$ for those with a maximum MPD diameter of $6.5 \mathrm{~mm}$ or greater. Because the surgeon's suspicion alone did not prove to be highly specific for MD-IPMN in the DPR, the use of endoscopy with MPD fluid aspirate analysis and EUS-guided pancreatic ductography is supported to assist with more accurate diagnosis. 


\section{REFERENCES}

1. Ohashi K, Murakami Y, Maruyama M, Takekoshi T, Ohta H. Four cases of mucous secreting pancreatic cancer. Prog Dig Endosc. 1982;20:348-51.

2. Brugge WR, Lauwers GY, Sahani D, Fernandez-del Castillo C, Warshaw AL. Cystic neoplasms of the pancreas. N Engl J Med. 2004;351:1218-26.

3. Tanaka M, Chari S, Adsay V, Fernandez-del Castillo C, Falconi M, Shimizu M, Yamaguchi K, Yamao K, Matsuno S. International consensus guidelines for management of intraductal papillary mucinous neoplasms and mucinous cystic neoplasms of the pancreas. Pancreatology. 2006;6:17-32.

4. Tanaka M, Fernandez-del Castillo C, Adsay V, Chari S, Falconi M, Jang JY, Kimura W, Levy P, Pitman MB, Schmidt CM, Shimizu M, Wolfgang CL, Yamaguchi K, Yamao K. International consensus guidelines 2012 for the management of IPMN and MCN of the pancreas. Pancreatology. 2012;12:183-97.

5. Yan L, Siddiqui AA, Laique SN, Saumoy M, Kahaleh M, Yoo J, Kalra A, Mathew A, Sterling J, Rao R, Lieberman M, Cosgrove N, Sharaiha RZ. A large multicenter study of recurrence after surgical resection of branch-duct intraductal papillary mucinous neoplasm of the pancreas. Minerva Gastroenterol Dietol. 2017;63:50-4.

6. Tamura K, Ohtsuka T, Ideno N, Aso T, Shindo K, Aishima S, Ohuchida K, Takahata S, Ushijima Y, Ito T, Oda Y, Mizumoto K, Tanaka M. Treatment strategy for main duct intraductal papillary mucinous neoplasms of the pancreas based on the assessment of recurrence in the remnant pancreas after resection: a retrospective review. Ann Surg. 2014;259:360-8.

7. Passot G, Lebeau R, Hervieu V, Ponchon T, Pilleul F, Adham M. Recurrences after surgical resection of intraductal papillary mucinous neoplasm of the pancreas: a singlecenter study of recurrence predictive factors. Pancreas. 2012;41:137-41.

8. Ohtsuka T, Kono H, Tanabe R, Nagayoshi Y, Mori Y, Sadakari Y, Takahata S, Oda Y, Aishima S, Igarashi H, Ito T, Ishigami K, Nakamura M, Mizumoto K, Tanaka M. Follow-up study after resection of intraductal papillary mucinous neoplasm of the pancreas; special references to the multifocal lesions and development of ductal carcinoma in the remnant pancreas. Am J Surg. 2012;204:44-8.

9. Moriya T, Traverso W. Fate of the pancreatic remnant after resection for an intraductal papillary mucinous neoplasm: a longitudinal level II cohort study. Arch Surg. 2012;147:528-34.

10. Blackham AU, Doepker MP, Centeno BA, Springett G, Pimiento JM, Malafa M, Hodul PJ. Patterns of recurrence and long-term outcomes in patients who underwent pancreatectomy for intraductal papillary mucinous neoplasms with high grade dysplasia: implications for surveillance and future management guidelines. HPB : the official journal of the International Hepato Pancreato Biliary Association. 2017;19:603-10.

11. Salvia R, Fernandez-del Castillo C, Bassi C, Thayer SP, Falconi M, Mantovani W, Pederzoli P, Warshaw AL. Main-duct intraductal papillary mucinous neoplasms of the pancreas: clinical predictors of malignancy and long-term survival following resection. Ann Surg. 2004;239:678-85; discussion 85-7.

12. Fujii T, Kato K, Kodera Y, Kanda M, Nagai S, Yamada S, Kanzaki A, Sugimoto H, Nomoto S, Takeda S, Morita S, Nakamura S, Nakao A. Prognostic impact of pancreatic 
margin status in the intraductal papillary mucinous neoplasms of the pancreas. Surgery. 2010;148:285-90.

13. Park J, Lee KT, Jang TH, Seo YW, Lee KH, Lee JK, Jang KT, Heo JS, Choi SH, Choi DW, Rhee JC. Risk factors associated with the postoperative recurrence of intraductal papillary mucinous neoplasms of the pancreas. Pancreas. 2011;40:46-51.

14. Tibayan F, Vierra M, Mindelzun B, Tsang D, McClenathan J, Young H, Trueblood HW. Clinical presentation of mucin-secreting tumors of the pancreas. Am J Surg. 2000;179:349-51.

15. Retter J, Dinter D, Bersch C, Singer MV, Lohr M. Acute recurrent pancreatitis curtaining an intraductal papillary mucinous tumor of the pancreas. J Gastrointestin Liver Dis. 2007;16:445-7.

16. Berger Z, De La Fuente H, Meneses M, Matamala F, Sepulveda M, Rojas C. Association of Chronic Pancreatitis and Malignant Main Duct IPMN: A Rare but Difficult Clinical Problem. Case reports in gastrointestinal medicine. 2017;2017:8705195.

17. Cioffi JL, McDuffie LA, Roch AM, Zyromski NJ, Ceppa EP, Schmidt CM, Nakeeb A, House MG. Pancreaticojejunostomy Stricture After Pancreatoduodenectomy: Outcomes After Operative Revision. J Gastrointest Surg. 2016;20:293-9.

18. Miura F, Takada T, Amano H, Yoshida M, Isaka T, Toyota N, Wada K, Takagi K, Kato K. Repeated pancreatectomy after pancreatoduodenectomy. J Gastrointest Surg. 2007;11:179-86.

19. Mallery S, Matlock J, Freeman ML. EUS-guided rendezvous drainage of obstructed biliary and pancreatic ducts: Report of 6 cases. Gastrointest Endosc. 2004;59:100-7.

20. Reid-Lombardo KM, Ramos-De la Medina A, Thomsen K, Harmsen WS, Farnell MB. Long-term anastomotic complications after pancreaticoduodenectomy for benign diseases. J Gastrointest Surg. 2007;11:1704-11.

21. Ryou M, Mullady DK, Dimaio CJ, Swanson RS, Carr-Locke DL, Thompson CC. Pancreatic antegrade needle-knife (PANK) for treatment of symptomatic pancreatic duct obstruction in Whipple patients (with video). Gastrointest Endosc. 2010;72:1081-8.

22. Barkay O, Sherman S, McHenry L, Yoo BM, Fogel EL, Watkins JL, DeWitt J, AlHaddad MA, Lehman GA. Therapeutic EUS-assisted endoscopic retrograde pancreatography after failed pancreatic duct cannulation at ERCP. Gastrointest Endosc. 2010;71:1166-73.

23. Takikawa T, Kanno A, Masamune A, Hamada S, Nakano E, Miura S, Ariga H, Unno J, Kume K, Kikuta K, Hirota M, Yoshida H, Katayose Y, Unno M, Shimosegawa T. Pancreatic duct drainage using EUS-guided rendezvous technique for stenotic pancreaticojejunostomy. World J Gastroenterol. 2013;19:5182-6.

24. Dumonceau JM, Cremer M, Baize M, Deviere J. The transduodenal rendezvous: a new approach to deeply cannulate the main pancreatic duct. Gastrointest Endosc. 1999;50:274-6.

25. Bataille L, Deprez P. A new application for therapeutic EUS: main pancreatic duct drainage with a "pancreatic rendezvous technique". Gastrointest Endosc. 2002;55:740-3.

26. Parikh P, Shiloach M, Cohen ME, Bilimoria KY, Ko CY, Hall BL, Pitt HA. Pancreatectomy risk calculator: an ACS-NSQIP resource. HPB : the official journal of the International Hepato Pancreato Biliary Association. 2010;12:488-97. 
27. Demirjian AN, Kent TS, Callery MP, Vollmer CM. The inconsistent nature of symptomatic pancreatico-jejunostomy anastomotic strictures. HPB : the official journal of the International Hepato Pancreato Biliary Association. 2010;12:482-7.

28. Morgan KA, Fontenot BB, Harvey NR, Adams DB. Revision of anastomotic stenosis after pancreatic head resection for chronic pancreatitis: is it futile? HPB : the official journal of the International Hepato Pancreato Biliary Association. 2010;12:211-6.

29. Mucci-Hennekinne S, Brachet D, Clouston H, Pessaux P, Hamy A, Arnaud JP. Management of a stenotic pancreatico-digestive tract anastomosis following pancreatoduodenectomy. J Hepatobiliary Pancreat Surg. 2007;14:514-7.

30. Wagle P, Yadav KS, Sali PA, Garg R, Varty P. Is Revision Surgery Justified for Symptomatic Pancreatico-enteric Anastomotic Stenosis in Long-term Survivors Following Pancreaticoduodenectomy for Malignancy? J Gastrointest Surg. 2017;21:33943.

31. Brook OR, Abedin S, Mortele KJ. Magnetic resonance imaging of the postoperative pancreas. Semin Ultrasound CT MR. 2013;34:325-35.

32. Raman SP, Horton KM, Cameron JL, Fishman EK. CT after pancreaticoduodenectomy: spectrum of normal findings and complications. AJR Am J Roentgenol. 2013;201:2-13.

33. Kim JH, Hong SS, Kim YJ, Kim JK, Eun HW. Intraductal papillary mucinous neoplasm of the pancreas: differentiate from chronic pancreatits by MR imaging. Eur J Radiol. 2012;81:671-6.

34. Miller JR, Meyer JE, Waters JA, Al-Haddad M, Dewitt J, Sherman S, Lillemoe KD, Schmidt CM. Outcome of the pancreatic remnant following segmental pancreatectomy for non-invasive intraductal papillary mucinous neoplasm. HPB : the official journal of the International Hepato Pancreato Biliary Association. 2011;13:759-66.

35. Nara S, Onaya H, Hiraoka N, Shimada K, Sano T, Sakamoto Y, Esaki M, Kosuge T. Preoperative evaluation of invasive and noninvasive intraductal papillary-mucinous neoplasms of the pancreas: clinical, radiological, and pathological analysis of 123 cases. Pancreas. 2009;38:8-16.

36. Kitagawa Y, Unger TA, Taylor S, Kozarek RA, Traverso LW. Mucus is a predictor of better prognosis and survival in patients with intraductal papillary mucinous tumor of the pancreas. J Gastrointest Surg. 2003;7:12-9.

37. Murakami Y, Uemura K, Hayashidani Y, Sudo T, Sueda T. Predictive factors of malignant or invasive intraductal papillary-mucinous neoplasms of the pancreas. $\mathrm{J}$ Gastrointest Surg. 2007;11:338-44.

38. Crippa S, Pergolini I, Rubini C, Castelli P, Partelli S, Zardini C, Marchesini G, Zamboni G, Falconi M. Risk of misdiagnosis and overtreatment in patients with main pancreatic duct dilatation and suspected combined/main-duct intraductal papillary mucinous neoplasms. Surgery. 2016;159:1041-9.

39. Shen J, Brugge WR, Dimaio CJ, Pitman MB. Molecular analysis of pancreatic cyst fluid: a comparative analysis with current practice of diagnosis. Cancer. 2009;117:217-27.

40. Al-Haddad M, DeWitt J, Sherman S, Schmidt CM, LeBlanc JK, McHenry L, Cote G, El Chafic AH, Luz L, Stuart JS, Johnson CS, Klochan C, Imperiale TF. Performance characteristics of molecular (DNA) analysis for the diagnosis of mucinous pancreatic cysts. Gastrointest Endosc. 2014;79:79-87.

41. Siddiqui AA, Kowalski TE, Kedika R, Roy A, Loren DE, Ellsworth E, Adler D, Finkelstein SD. EUS-guided pancreatic fluid aspiration for DNA analysis of KRAS and 
GNAS mutations for the evaluation of pancreatic cystic neoplasia: a pilot study. Gastrointest Endosc. 2013;77:669-70.

42. Wu J, Matthaei H, Maitra A, Dal Molin M, Wood LD, Eshleman JR, Goggins M, Canto MI, Schulick RD, Edil BH, Wolfgang CL, Klein AP, Diaz LA, Jr., Allen PJ, Schmidt CM, Kinzler KW, Papadopoulos N, Hruban RH, Vogelstein B. Recurrent GNAS mutations define an unexpected pathway for pancreatic cyst development. Sci Transl Med. 2011;3:92ra66.

43. Morris-Stiff G, Lentz G, Chalikonda S, Johnson M, Biscotti C, Stevens T, Matthew Walsh R. Pancreatic cyst aspiration analysis for cystic neoplasms: mucin or carcinoembryonic antigen--which is better? Surgery. 2010;148:638-44; discussion 44-5.

44. Khalid A, McGrath KM, Zahid M, Wilson M, Brody D, Swalsky P, Moser AJ, Lee KK, Slivka A, Whitcomb DC, Finkelstein S. The role of pancreatic cyst fluid molecular analysis in predicting cyst pathology. Clin Gastroenterol Hepatol. 2005;3:967-73.

45. Das K, Kochhar R, Mehta SK, Suri S. Ultrasound guided pancreatic ductography. Indian J Gastroenterol. 1990;9:129-30.

46. Xiao SY. Intraductal papillary mucinous neoplasm of the pancreas: an update. Scientifica. 2012;2012:893632.

Author names in bold designate shared co-first authorship. 


\section{TABLES}

Table 1. Characteristics of Patients with Malignant $(n=24)$ Versus Benign $(n=200)$

\section{Outcomes During Surveillance of the Distal Pancreatic Remnant}

\begin{tabular}{|c|c|c|c|c|c|c|c|c|}
\hline & Malignant & Benign & P-value & Sn & Sp & Acc & PPV & NPV \\
\hline \multicolumn{9}{|l|}{ Proximal Pancreatectomy Variables } \\
\hline High Grade/Invasive Pathology & $24 / 24(100 \%)$ & $66 / 192(34.4 \%)$ & $<0.001$ & $100.0 \%$ & $65.6 \%$ & $69.4 \%$ & $26.7 \%$ & $100.0 \%$ \\
\hline Invasive Pathology & $23 / 24(95.8 \%)$ & $32 / 192(16.7 \%)$ & $<0.001$ & $95.8 \%$ & $83.3 \%$ & $84.7 \%$ & $41.8 \%$ & $99.4 \%$ \\
\hline MD-IPMN & $11 / 17(64.7 \%)$ & $109 / 198(55.1 \%)$ & 0.442 & $64.7 \%$ & $44.9 \%$ & $46.5 \%$ & $9.2 \%$ & $93.7 \%$ \\
\hline Positive Margin & $8 / 24(33.3 \%)$ & $47 / 200(23.5 \%)$ & 0.290 & $33.3 \%$ & $76.5 \%$ & $71.9 \%$ & $14.5 \%$ & $90.5 \%$ \\
\hline \multicolumn{9}{|l|}{ Post Proximal-Pancreatectomy Radiographic Variables } \\
\hline *Time to 1st Dilated Duct (days) & $277(57-2031)$ & $370(5-3651)$ & 0.905 & - & - & - & - & - \\
\hline *Time to 1st Dilated Duct if Normal pre-PP (days) & $1215(277-2031)$ & $525.5(7-3651)$ & 0.635 & - & - & - & - & - \\
\hline *MPD Maximum Diameter (mm) & $5(5-5)$ & $6(5-13)$ & 0.386 & - & - & - & - & - \\
\hline *Time to Maximum Dilated Duct (days) & $277(277-277)$ & $455.5(7-3651)$ & 0.456 & - & - & - & - & - \\
\hline Dilated Remnant Duct & $5 / 24(20.8 \%)$ & $66 / 200(33.0 \%)$ & 0.226 & $20.8 \%$ & $67.0 \%$ & $62.1 \%$ & $7.0 \%$ & $87.6 \%$ \\
\hline *Dilation Decreasing from Maximum to Most Recent & $3 / 5(60.0 \%)$ & $42 / 60(70.0 \%)$ & 0.639 & $60.0 \%$ & $30.0 \%$ & $32.3 \%$ & $6.7 \%$ & $90.0 \%$ \\
\hline *Dilation Resolved from Maximum to Most Recent & $2 / 3(66.7 \%)$ & $31 / 59(52.5 \%)$ & 1.000 & $66.7 \%$ & $47.5 \%$ & $48.4 \%$ & $6.1 \%$ & $96.6 \%$ \\
\hline \multicolumn{9}{|l|}{ Post Proximal-Pancreatectomy Clinical Variables } \\
\hline Maximum Surveillance CA 19-9(U/mL) & $669(3-67107)$ & $23(1-81954)$ & $<0.001$ & - & - & - & - & - \\
\hline Most Recent Surveillance CA 19-9 (U/mL) & $556(3-67107)$ & $18(1-81954)$ & $<0.001$ & - & - & - & - & - \\
\hline Uptrending CA 19-9 & $8 / 22(36.4 \%)$ & $35 / 112(31.25 \%)$ & 0.639 & $36.4 \%$ & $68.8 \%$ & $63.4 \%$ & $18.6 \%$ & $84.6 \%$ \\
\hline \multicolumn{9}{|c|}{$\begin{array}{l}\text { Categorical variables expressed as } \mathrm{N} \text {-positive/N-tested (\%); Continuous variables with normal distribution expressed as mean (standard error of the mean); } \\
\text { Continuous variables with non-normal distribution expressed as median (range); MPD Main Pancreatic Duct }\end{array}$} \\
\hline \multicolumn{9}{|c|}{ *indicates this feature is only pertinent to patients with a dilated main pancreatic duct (malignant $n=5$, benign $n=66$ ) } \\
\hline
\end{tabular}


Table 2. Characteristics of Patients with MD-IPMN $(n=7)$ or No MD-IPMN $(n=14)$ on Re-

\section{Operative Surgical Pathology of the Distal Pancreatic Remnant}

\begin{tabular}{|c|c|c|c|c|c|c|c|c|}
\hline & MD-IPMN & No MD-IPMN & P-value & Sn & Sp & Acc & PPV & NPV \\
\hline \multicolumn{9}{|l|}{ Proximal Pancreatectomy Variables } \\
\hline MPD Diameter Pre-Op (mm) & $6(2-12)$ & $4(1.6-15)$ & 0.503 & - & - & - & - & - \\
\hline Dilated Duct Pre-Op & $4 / 6(66.7 \%)$ & $5 / 13(38.5 \%)$ & 0.350 & $66.7 \%$ & $61.5 \%$ & $63.2 \%$ & $44.4 \%$ & $80.0 \%$ \\
\hline High Grade/Invasive Pathology & $2 / 7(28.6 \%)$ & $5 / 13(38.5 \%)$ & 1.000 & $28.6 \%$ & $61.5 \%$ & $50.0 \%$ & $28.6 \%$ & $61.5 \%$ \\
\hline Invasive Pathology & $2 / 7(28.6 \%)$ & $1 / 13(7.7 \%)$ & 0.270 & $28.6 \%$ & $92.3 \%$ & $70.0 \%$ & $66.7 \%$ & $70.6 \%$ \\
\hline MD-IPMN & $4 / 7(57.1 \%)$ & $8 / 14(57.1 \%)$ & 1.000 & $57.1 \%$ & $42.9 \%$ & $47.6 \%$ & $33.3 \%$ & $66.7 \%$ \\
\hline Positive Margin & $2 / 6(33.3 \%)$ & $2 / 14(14.3 \%)$ & 0.549 & $33.3 \%$ & $85.7 \%$ & $70.0 \%$ & $50.0 \%$ & $75.0 \%$ \\
\hline \multicolumn{9}{|c|}{ Pre-Distal Remnant Resection Radiographic Variables } \\
\hline *Time to 1st Dilated Duct Pre-Op (days) & $341(96-2651)$ & $398(8-981)$ & 1.000 & - & - & - & - & - \\
\hline MPD Maximum Diameter Pre-Op (mm) & $9.5(1.5)$ & $6.2(0.5)$ & 0.072 & - & - & - & - & - \\
\hline Time to Maximum Diameter Pre-Op (days) & $618(112-2993)$ & $801(187-2740)$ & 1.000 & - & - & - & - & - \\
\hline MPD Diameter Immediately Pre-Op (mm) & $7.4(1.8)$ & $5.6(0.5)$ & 0.355 & - & - & - & - & - \\
\hline Dilated Duct Pre-Op & $7 / 7(100 \%)$ & $13 / 14(92.9 \%)$ & 1.000 & $100.0 \%$ & $7.1 \%$ & $38.1 \%$ & $35.0 \%$ & $100.0 \%$ \\
\hline *Dilation Decreased from Maximum to PreOp & $4 / 7(57.1 \%)$ & $5 / 13(38.5 \%)$ & 0.642 & $57.1 \%$ & $61.5 \%$ & $60.0 \%$ & $44.4 \%$ & $72.7 \%$ \\
\hline *Dilation Resolves from Maximum to Preop & $2 / 7(28.6 \%)$ & $2 / 13(15.4 \%)$ & 0.587 & $28.6 \%$ & $84.6 \%$ & $65.0 \%$ & $50.0 \%$ & $68.8 \%$ \\
\hline${ }^{*}$ Good Secretin Response on MRCP & $2 / 3(66.7 \%)$ & $6 / 12(50.0 \%)$ & 1.000 & $66.7 \%$ & $50.0 \%$ & $53.3 \%$ & $25.0 \%$ & $85.7 \%$ \\
\hline \multicolumn{9}{|c|}{ Pre-Distal Remnant Resection Endoscopic Variables } \\
\hline Endoscopist Suggests MD-IPMN & $3 / 7(42.9 \%)$ & $2 / 12(16.7 \%)$ & 0.305 & $42.9 \%$ & $83.3 \%$ & $68.4 \%$ & $60.0 \%$ & $71.4 \%$ \\
\hline Endoscopy Not Suggestive of Stricture & $5 / 7(71.4 \%)$ & $5 / 12(41.7 \%)$ & 0.350 & $71.4 \%$ & $58.3 \%$ & $63.2 \%$ & $50.0 \%$ & $77.8 \%$ \\
\hline Normal Ductogram & $1 / 3(33.3 \%)$ & $1 / 8(12.5 \%)$ & 0.491 & $33.3 \%$ & $87.5 \%$ & $72.7 \%$ & $50.0 \%$ & $77.8 \%$ \\
\hline \multicolumn{9}{|l|}{ Pre-Distal Remnant Resection Clinical Variables } \\
\hline Pre-DPR Re-Operation CA 19-9 (U/mL) & $30(6-237)$ & $23(3-4722)$ & 0.913 & - & - & - & - & - \\
\hline Any Symptoms & $7 / 7(100.0 \%)$ & $13 / 14(92.9 \%)$ & 1.000 & $100.0 \%$ & $7.1 \%$ & $38.1 \%$ & $35.0 \%$ & $100.0 \%$ \\
\hline Pancreatitis & $4 / 7(57.1 \%)$ & $9 / 14(64.3 \%)$ & 1.000 & $57.1 \%$ & $35.7 \%$ & $42.9 \%$ & $30.8 \%$ & $62.5 \%$ \\
\hline Exocrine Insufficiency & $7 / 7(100.0 \%)$ & $9 / 14(64.3 \%)$ & 0.123 & $100.0 \%$ & $35.7 \%$ & $57.1 \%$ & $43.8 \%$ & $100.0 \%$ \\
\hline Abdominal Pain & $6 / 7(85.7 \%)$ & $10 / 14(71.4 \%)$ & 0.624 & $85.7 \%$ & $28.6 \%$ & $47.6 \%$ & $37.5 \%$ & $80.0 \%$ \\
\hline Weight Loss & $4 / 7(57.1 \%)$ & $4 / 14(28.6 \%)$ & 0.346 & $57.1 \%$ & $71.4 \%$ & $66.7 \%$ & $50.0 \%$ & $76.9 \%$ \\
\hline Surgeon's Concern for MD-IPMN & $5 / 7(71.4 \%)$ & $9 / 14(64.3 \%)$ & 1.000 & $71.4 \%$ & $35.7 \%$ & $47.6 \%$ & $35.7 \%$ & $71.4 \%$ \\
\hline Uptrending CA $19-9$ & $4 / 6(66.7 \%)$ & $7 / 11(63.6 \%)$ & 1.000 & $66.7 \%$ & $36.4 \%$ & $47.1 \%$ & $36.4 \%$ & $66.7 \%$ \\
\hline
\end{tabular}




\title{
Supplemental Table 1. Pancreatic Duct Fluid Analysis for Patients With a) Malignant
}

\author{
$(n=24)$ Versus Benign $(n=200)$ Outcomes During Surveillance of the Distal Pancreatic
}

Remnant and b) Patients with MD-IPMN (n=7) or No MD-IPMN (n=14) on Re-Operative

\section{Surgical Pathology of the Distal Pancreatic Remnant}

\begin{tabular}{|c|c|c|c|c|c|c|c|c|}
\hline \multicolumn{9}{|c|}{ a. Post Proximal-Pancreatectomy Pancreatic Duct Fluid Analysis } \\
\hline & Malignant & Benign & P-value & Sn & Sp & Acc & PPV & NPV \\
\hline MPD Aspirate CEA (ng/mL) & - & $167(0.3-12120)$ & - & - & - & - & - & - \\
\hline MPD Aspirate CEA > 192 & $0 / 0(0.0 \%)$ & $7 / 14(50.0 \%)$ & - & - & $50.0 \%$ & $50.0 \%$ & $0.0 \%$ & $100.0 \%$ \\
\hline MPD Aspirate + Mucin & $0 / 0(0.0 \%)$ & $5 / 14(27.8 \%)$ & - & - & $72.2 \%$ & $72.2 \%$ & $0.0 \%$ & $100.0 \%$ \\
\hline MPD Aspirate Cytology (HGD/CA) & $1 / 1(100.0 \%)$ & $0 / 18(0.0 \%)$ & 0.053 & $100.0 \%$ & $100.0 \%$ & $100.0 \%$ & $100.0 \%$ & $100.0 \%$ \\
\hline MPD Aspirate High Quantity DNA & $0 / 0(0.0 \%)$ & $9 / 12(75.0 \%)$ & - & - & $25.0 \%$ & $25.0 \%$ & $0.0 \%$ & $100.0 \%$ \\
\hline MPD Aspirate High Quality DNA & $0 / 0(0.0 \%)$ & $4 / 12(33.3 \%)$ & - & - & $66.7 \%$ & $66.7 \%$ & $0.0 \%$ & $100.0 \%$ \\
\hline MPD Aspirate KRAS $\underline{\text { OR GNAS }}$ & $0 / 0(0.0 \%)$ & $1 / 11(9.1 \%)$ & - & - & $90.9 \%$ & $90.9 \%$ & $0.0 \%$ & $100.0 \%$ \\
\hline MPD Aspirate KRAS & $0 / 0(0.0 \%)$ & $1 / 11(9.1 \%)$ & - & - & $90.9 \%$ & $90.9 \%$ & $0.0 \%$ & $100.0 \%$ \\
\hline MPD Aspirate GNAS & $0 / 0(0.0 \%)$ & $0 / 2(0.0 \%)$ & - & - & $100.0 \%$ & $100.0 \%$ & $0.0 \%$ & $100.0 \%$ \\
\hline MPD Aspirate LOH & $0 / 0(0.0 \%)$ & $0 / 7(0.0 \%)$ & - & - & $100.0 \%$ & $100.0 \%$ & $0.0 \%$ & $100.0 \%$ \\
\hline \multicolumn{9}{|c|}{ b. Pre-Distal Remnant Resection Pancreatic Duct Fluid Analysis } \\
\hline & MD-IPMN & No MD-IPMN & P-value & Sn & Sp & Acc & PPV & NPV \\
\hline MPD Aspirate CEA (ng/mL) & $114(15-28505)$ & $108(12-672)$ & 0.786 & 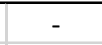 & 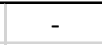 & - & - & - \\
\hline MPD Aspirate CEA > 192 & $1 / 3(33.3 \%)$ & $2 / 5(40.0 \%)$ & 1.000 & $33.3 \%$ & $60.0 \%$ & $50.0 \%$ & $33.3 \%$ & $60.0 \%$ \\
\hline MPD Aspirate + Mucin & $4 / 5(80.0 \%)$ & $3 / 8(37.5 \%)$ & 0.266 & $80.0 \%$ & $62.5 \%$ & $69.2 \%$ & $57.1 \%$ & $83.3 \%$ \\
\hline MPD Aspirate Cytology (HGD/CA) & $1 / 5(20.0 \%)$ & $0 / 8(0.0 \%)$ & 0.385 & $20.0 \%$ & $100.0 \%$ & $69.2 \%$ & $100.0 \%$ & $66.7 \%$ \\
\hline MPD Aspirate High Quantity DNA & $3 / 3(100.0 \%)$ & $3 / 5(60.0 \%)$ & 0.464 & $100.0 \%$ & $40.0 \%$ & $62.5 \%$ & $50.0 \%$ & $100.0 \%$ \\
\hline MPD Aspirate High Quality DNA & $2 / 3(66.7 \%)$ & $1 / 5(20.0 \%)$ & 0.464 & $66.7 \%$ & $80.0 \%$ & $75.0 \%$ & $66.7 \%$ & $80.0 \%$ \\
\hline MPD Aspirate KRAS OR GNAS & $1 / 3(33.3 \%)$ & $0 / 4(0.0 \%)$ & 0.429 & $33.3 \%$ & $100.0 \%$ & $71.4 \%$ & $100.0 \%$ & $66.7 \%$ \\
\hline MPD Aspirate KRAS & $0 / 3(0.0 \%)$ & $0 / 4(0.0 \%)$ & - & $0.00 \%$ & $100.0 \%$ & $57.4 \%$ & - & $57.1 \%$ \\
\hline MPD Aspirate GNAS & $1 / 2(50.0 \%)$ & $0 / 4(0.0 \%)$ & 0.333 & $50.0 \%$ & $100.0 \%$ & $83.3 \%$ & $100.0 \%$ & $80.0 \%$ \\
\hline MPD Aspirate LOH & $1 / 3(33.3 \%)$ & $0 / 3(0.0 \%)$ & 1.000 & $33.3 \%$ & $100.0 \%$ & $66.7 \%$ & $100.0 \%$ & $60.0 \%$ \\
\hline
\end{tabular}




\section{FIGURE LEGENDS}

Figure 1. Overall Surveillance Outcomes by Proximal Pancreatectomy Surgical Pathology

Figure 2. Median Time to Outcome Determination by Proximal Pancreatectomy Surgical Pathology

Figure 3. Receiver Operating Characteristic Curve for Maximum Main Pancreatic Duct Diameter in the Distal Pancreatic Remnant and MD-IPMN on Distal Pancreatic Remnant Surgical Pathology

Figure 4. Proposed Management Algorithm for the Distal Pancreatic Remnant 


\section{FIGURES}

Figure 1.

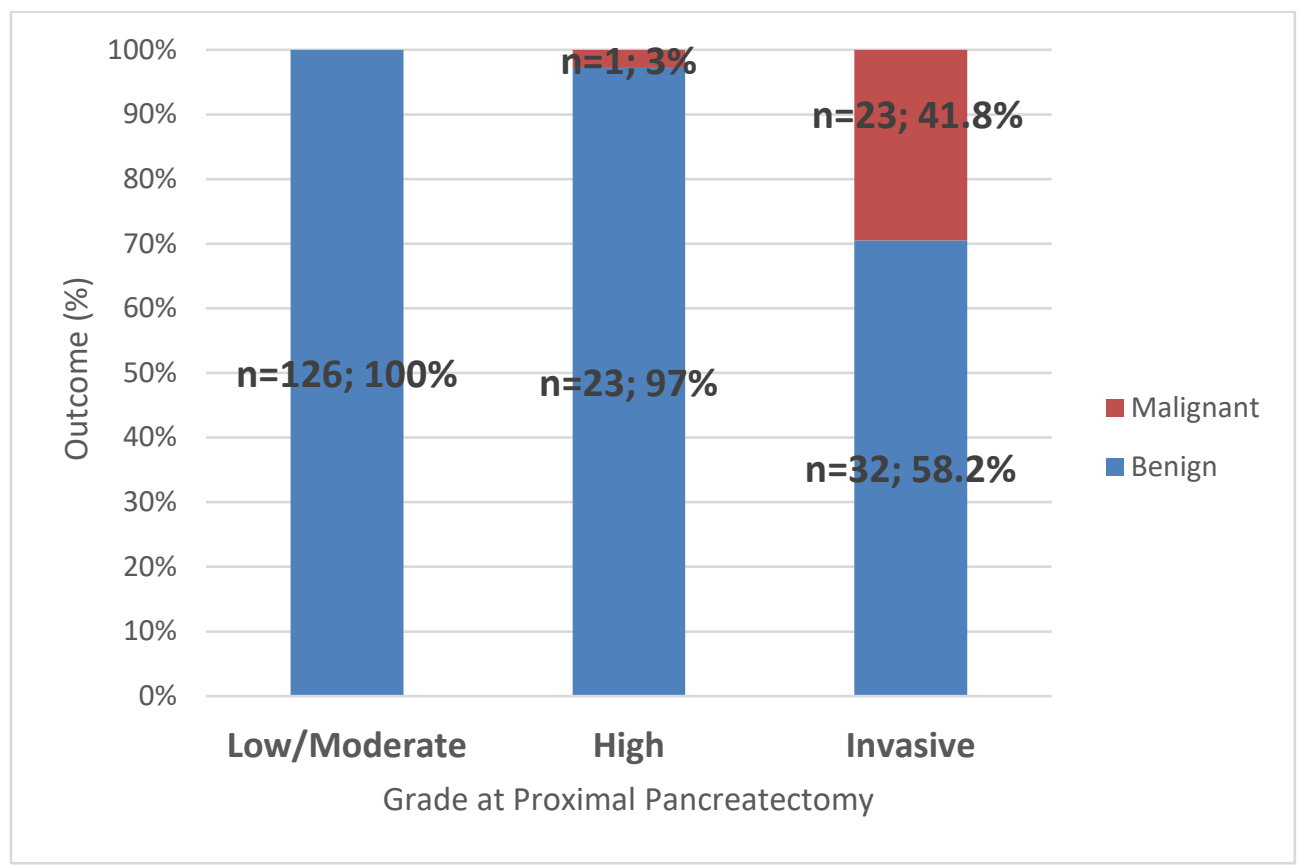


Figure 2.

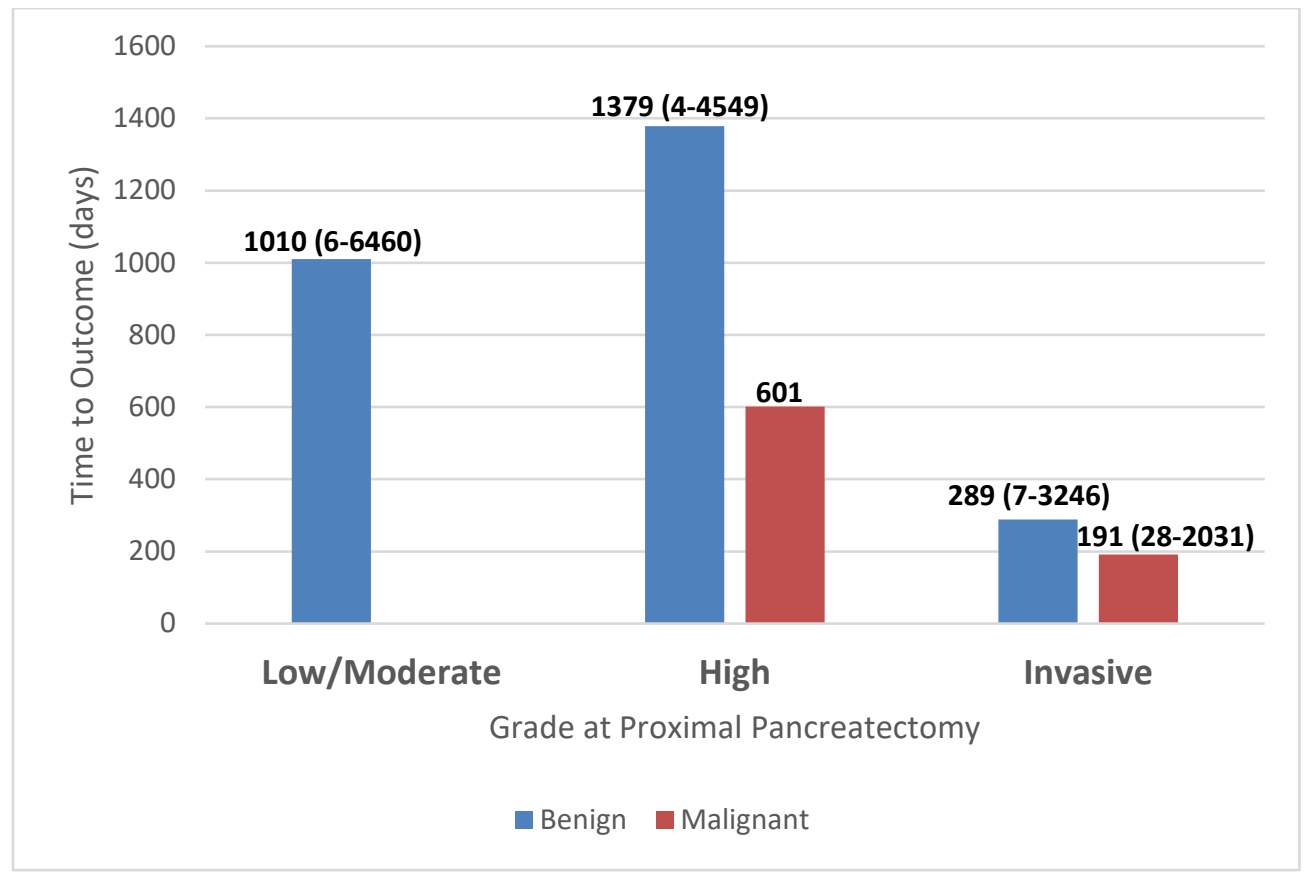


Dilemma Dilated MPD Remnant

Figure 3.

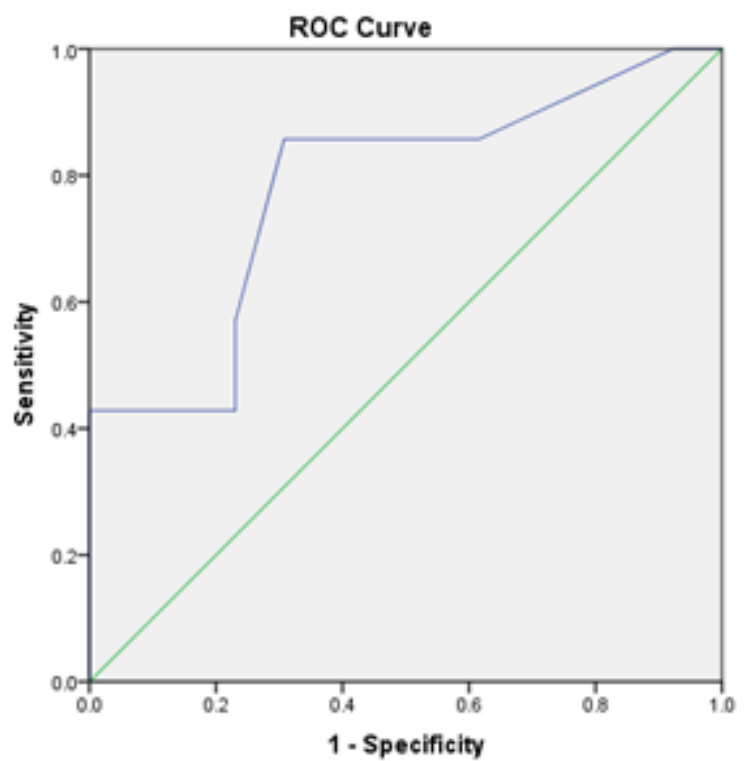




\section{Figure 4 .}

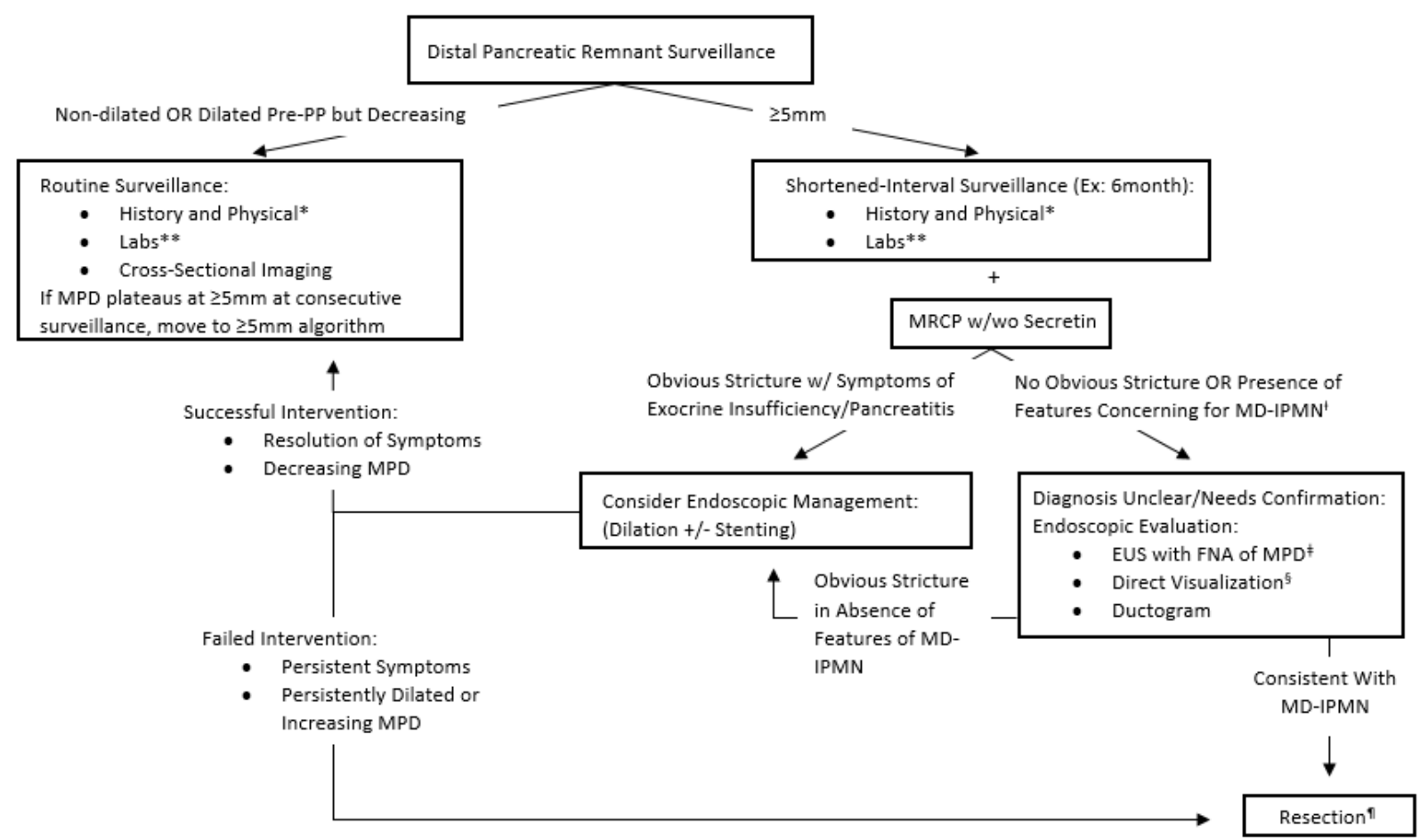

MPD Main Pancreatic Duct; MD-IPMN Main Duct IPMN; EUS Endoscopic Ultrasound; FNA Fine-Needle Aspiration. *History of diarrhea/steatorrhea, new/worsening diabetes, epigastric abdominal pain, unintentional weight loss, pancreatitis. -•Serum amylase, lipase, alkaline phosphatase, CA 19-9, CEA, hemoglobin A1c, c-peptide. † Mural

nodules, thickened MPD walls, filling defects. ¥MPD aspirate mucin, CEA $>192 \mathrm{ng} / \mathrm{mL}$, DNA profiling (KRAS/GNAS mutation), cytology. §ु Confocal microscopy, ductoscopy. ๆ Consider anastomotic revision with frozen section, resect to negative MPD margins understanding completion pancreatectomy may be required 